\title{
ANALISA DAMPAK PERKEMBANGAN PEMBANGUNAN INFRASTRUKTUR TERHADAP MASYARAKAT PERMUKIMAN (STUDI KASUS JALAN PASAR NAMBANGAN, KENJERAN, SURABAYA)
}

\author{
Muhammad Aunirrouf ${ }^{1}$, Ronny Durrotun Nasihien ${ }^{2}$ \\ ${ }^{1}$ Prodi Teknik Sipil, Universitas Narotama, rkecil07@gmail.com \\ ${ }_{2}^{2}$ Prodi Teknik Sipil, Universitas Narotama, ronny.durrotun@narotama.ac.id
}

\begin{abstract}
ABSTRAK
Dampak dari perkembangan pembangunan Infrastruktur tehadap Masyarakat Kawasan Permukiman di Jalan Pasar Nambangan, Kenjeran, Surabaya perlu di evaluasi terhadap Jalan dan Saluran sepanjang 700 meter yang telah terpasang dilokasi dan dicari kepuasan Masyarkat setempat setelah dibangunnya Infrastruktur tersebut. Dengan menggunakan beberapa metode diantaranya mencari kualitas paving, menganalisa curah hujan menggunakan metode Log Person III,dan Mencari Kepuasan Masyarakat sebagai tolak ukur dari peneliti ini, dimana hasil dari masing-masing analisa dengan hasil optimal, dimana Jalan berupa Paving block menggunakan mutu beton I dengan tegangan hancur 38.22 Mpa yang akan berdampak pada umur jalan dan dalam kategori baik, lalu untuk saluran menghasilkan perbandingan Q Saluran dengan Q Rencana $0.104237837 \mathrm{~m} 3 /$ detik : $0.051493258 \mathrm{~m} 3 /$ detik, yang dimana (Kondisi saluran aman atau mampu menerima $Q$ Rencana) yang nantinya akan berdampak pada kapasitas saluran dalam 10 tahun kedepan dan yang terakhir adalah dari 75 Responden Masyarakat menunjukan 54.22\% Sangat Puas dari adanya Infrastruktur tersebut yang berdampak baik untuk menunjang aktifitas dalam sehari-hari masyarakat.
\end{abstract}

Kata kunci: Infrastruktur Kawasan Permukiman, Infrastruktur Jalan dan Saluran, Kepuasan Masyarakat

\section{PENDAHULUAN}

Infrastruktur adalah sebuah kebutuhan dasar sebagai pengoperasian alur aktifitas dalam sehari-hari supaya lancar dan optimal, bisa berupa jalan, saluran, air bersih, pelayanan publik, listrik, bangunan umum bisa berupa (terminal, pelabuhan, bandara, stasiun kereta api) dalam hal ini juga akan bisa menunjang dari segi ekonomi masyarakat sebagai subjek yang melalui atau menggunakan infrastruktur tersebut.

Tidak lupa juga Infrastuktur adalah sebagai tanggung jawab dari pemerintah daerah setempat yang dimana untuk kelancaran aktifitas publik sebagai sistem perencanaan pembangunan daerah yang merata dan semua bisa merasakan akan adanya perkembangan. Infrastuktur yang akan dibahas disini meliputi jalan, saluran, dan lingkungan yang terfasilitasi oleh jalan dan saluran tersebut.

Dengan seiring berjalannya waktu juga dan kemajuan pada zaman ini, tidak dipungkiri bahwa kehidupan dimasyarakat juga semakin meningkat, dari segi kebutuhan rumah tangga, akses mobilisasi dalam beraktifitas, kelayakan hidup pada lingkungan meliputi kebersihan dan perkembangan Infrastruktur yang cukup memadai di masyarakat tersebut.

Kehidupan masyarakat di Jalan Nambangan Perak, Kenjeran, Surabaya ini juga membutuhkan adanya perkembangan infrastruktur yang memadahi untuk segala aktifitas, kehidupan warga disini kurang lebih berprofesi sebagai nelayan ataupun 


\section{NAROTAMA JURNAL TEKNIK SIPIL \\ e-ISSN: $2460-3430$ \\ VOLUME 3 NOMOR 2 NOVEMBER 2019}

penjual ikan, dengan lokasi pada pesisir Surabaya pada bagian utara ini jelas perdampingan langsung pada laut.

Kebanyakan dari warga di Jalan Nambangan Perak, Kenjeran, Surabaya kurangnya berperilaku hidup sehat dengan membuang sampah pada saluran seghingga bisa menghambat aliran air yang menuju ke pembuangan utama / tersier yaitu laut sebagai pembuangan akhir, dan dilokasi ini juga sebelumnya belum ada infrastruktur pada akses jalan utama dengan kondisi jalan berupa tanah, dengan panjang jalan kurang lebih 700 meter dan dengan lebar kondisi eksiting dilapangan kurang lebih 3 meter beserta saluran dengan lebar saluran 50 centimeter.

Dalam penelitian ini nantinya akan dibahas sebagai perumusan masalah yaitu Apa yang berdampak pada masyarakat setelah adanya Pembangunan Infrastruktur berupa Jalan?, Apa yang berdampak pada masyarakat setelah adanya Pembangunan Infrastruktur berupa Saluran?, Apa tanggapan masyarakat terhadap adanya Pembangunan Infrastruktur berupa Jalan dan Saluran?.

Dengan batasan masalah yaitu Menganalisa Infrastuktur berupa jalan eksiting yang sudah ada terhadap perilaku masyarakat, Menganalisa Infrastuktur berupa saluran eksiting yang sudah ada terhadap perilaku masyarakat, Pengaruh perilaku masyarakat terhadap lingkungan setelah adanya infrastuktur berupa jalan dan saluran.

\section{LANDASAN TEORI}

Pada landasan Teori ini membahas tentang metode atau cara yang digunakan dalam penelitian ini meliputi kajian dan juga perhitungan yang berhubungan dengan subjek yang di teliti dimana akan mengemukakan ringkasan teori yang diambil dari sumber penelitian terdahulu bisa berasal dari Jurnal, Buku Pedoman dan Buku SNI.

Dalam penelitian ini dimana landasan teori yang diambil adalah tentang Infrastruktur, diantaranya ada 2 hal yaitu berupa jalan dan saluran, dan ada 1 penelitian juga membahas tentang kepuasan masyarakat terhadap infrastruktur, maka akan ada 3 teori yang diambil, yaitu Analisa Jalan berupa Kuat tekan paving dan daya serap air, Analisa Saluran ini untuk menganalisa Curah hujan menggunakan metode Log Person tipe III, Uji Chi Kuadrat, Koefisien Pengaliran (C), Perencanaan debit air buangan domestik (Qak), lalu teori yang ke tiga adalah menghitung Indeks Kepuasan Masyarakat (IKM).

Untuk pembahasan teori yang digunakan adalah sebagai berikut; terlebih dahulu adalah analisa jalan ( Kualitas paving blok) dengan sumber berasal dari (Anita Christine Sembiring,2017,Uji Kuat Tekan Dan Serapan Air Pada Paving Block dengan Bahan Pasir Kasar, Batu Kacang, dan Pasir Halus).

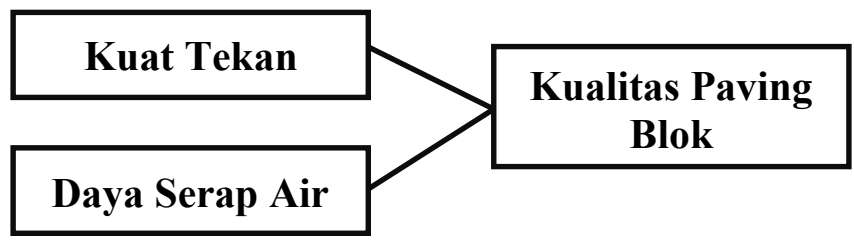

Gambar 1. Hubungan Kuat Tekan dan Daya Serap Air Terhadap Kualitas Paving

Uji tekan Paving Block dihitung menggunakan rumus :

$\boldsymbol{P}=\frac{\boldsymbol{F}}{\boldsymbol{A}} \&$ Daya Serap air $=$ 
lalu selanjutnya membahas Analisa saluran (Analisa Curah Hujan), dengan pembahasan sebagai berikut ;

Menghitung rata-rata curah hujan harian dalam bentuk logaritma

$\log x=\frac{\sum_{t=1}^{n} \log \mathrm{xi}}{n}$

Menghitung nilai standar deviasi yang terjadi (Sx)

$s x=\sqrt{\frac{\sum_{t=1}^{n} \log x i-\log x}{(n-1)}}$

Menghitung koefisien kepencengan (Cs)

$C s=\frac{\sum_{t=1}^{n}(\log x i-\log x)^{3}}{(n-1)(n-2) S x^{3}}$

Menghitung logaritma curah hujan untuk kala ulang 2 tahun:

$\log \mathrm{RTr}=\log \mathrm{x}+\mathrm{GxSxmakaRTr}=10^{\log R T r}$

Koefisien Pengaliran (C)

$C m=\frac{\sum_{i=1}^{n} A i . C i}{\sum_{i=1}^{n} A i}$

Perhitungan Debit Air Hujan (Qah)

$Q=\frac{1}{36} \times C \times I \times A$ dan $\mathbf{Q}$ ak Total $=\frac{\mathbf{P}_{\mathbf{n}} \times \mathbf{8 0} \% \times \mathbf{K}_{\mathrm{ab}}}{\mathbf{A}_{\text {total }}} \mathbf{m a k a Q a k}=$ Qak total $\times$ Aasal.

lalu untuk mengtahui kelayakan dari perhitungan adalah sebagai berikut ;

Q kapasitas saluran : Q Rencana

Dimana dikatakan layak adalah $\boldsymbol{Q}$ kapasitas saluran $>\boldsymbol{Q}$ Rencana, lalu dikatakan tidak layak $\boldsymbol{Q}$ kapasitas saluran $<\boldsymbol{Q}$ Rencana, Untuk analisa kepuasan masyarakat menggunakan indeks penilaian

Tabel 1. Analisa Kepuasan Masyarakat

\begin{tabular}{|c|c|c|c|c|c|c|c|c|}
\hline \multirow{2}{*}{$\begin{array}{c}\begin{array}{c}\text { Nilai } \\
\text { Persepsi }\end{array} \\
1\end{array}$} & \multicolumn{3}{|c|}{ Nilai Interval IKM } & \multicolumn{3}{|c|}{$\begin{array}{c}\text { Nilai Interval } \\
\text { Konvers ensi IKM }\end{array}$} & \multirow{2}{*}{$\begin{array}{c}\begin{array}{c}\text { Mutu } \\
\text { Pelayanan }\end{array} \\
\text { D }\end{array}$} & \multirow{2}{*}{$\begin{array}{c}\text { Penilaia Kinerja } \\
\text { Tidak Puas }\end{array}$} \\
\hline & 1.00 & & 1.72 & 25 & & 39.2 & & \\
\hline 2 & 1.82 & - & 2.54 & 40.2 & - & 54.4 & $\mathrm{C}$ & Kurang Puas \\
\hline 3 & 2.64 & - & 3.36 & 55.4 & - & 69.6 & $\mathrm{BC}$ & Cukup Puas \\
\hline 4 & 3.46 & $=$ & 4.18 & 70.6 & & 84.8 & $\mathrm{~B}$ & Puas \\
\hline 5 & 4.28 & - & 5.00 & 85.8 & - & 100 & A & Sangat Puas \\
\hline
\end{tabular}

Dengan perhitungan prosentase dari masing-masing indeks :

$\frac{\text { Qty Kinerja }}{\text { Total Qty Kinerja }} \times 100 \%$ 
NAROTAMA JURNAL TEKNIK SIPIL

e-ISSN: 2460-3430

VOLUME 3 NOMOR 2 NOVEMBER 2019

\section{METODOLGI PENELITIAN}

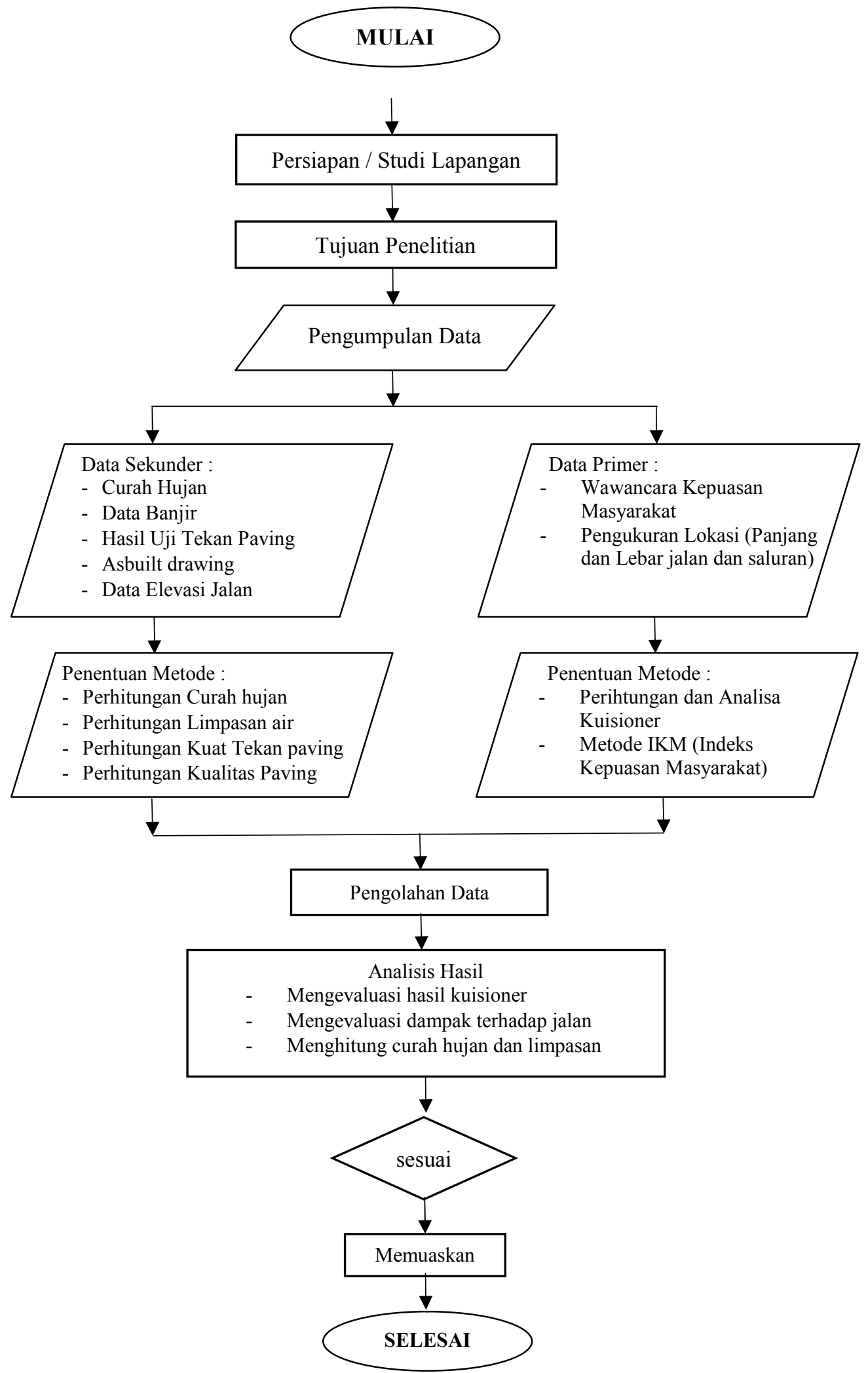

Gambar 2. Diagram Alur Penelitian 


\section{NAROTAMA JURNAL TEKNIK SIPIL \\ e-ISSN: 2460-3430 \\ VOLUME 3 NOMOR 2 NOVEMBER 2019}

\section{PEMBAHASAN}

\subsection{Penelitian Jalan}

Penelitian Jalan ini berupa Perkerasan komposit (compsite pavement), ada 2 bagian perhitungan yang pertama menggunakan data Sekunder, data sekunder ini adalah data dari uji laboratorium, ada 2 pengujian Kuat tekan paving dan Daya serap air / Ketahanan aus paving ; Lalu dengan hasil masing-masing sampling dan hasil uji tekan

Dari hasil perhitngan diatas maka, keseluruhan hasil Paving mempunyai mutu beton I dengan nilai f'c rata-rata $=\mathbf{3 8 . 2 2}$ Mpa dan Sampel ke 13 menunjukkan Nilai tertinggi yaitu $=39.60$ Mpa lalu dengan hasil terendah pada Sampel ke 8 yaitu 36.30 Mpa., berikut dijelakan pada Gambar 3.

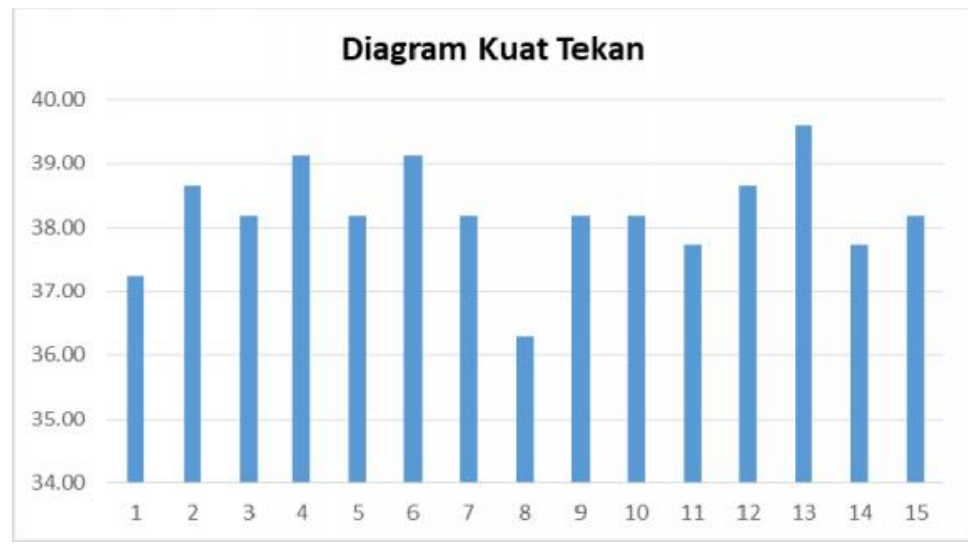

Gambar 3. Diagram Kuat Tekan

Dengan hasil perhitungan Daya Serap Air menghasilkan daya serap dibawah 1\% dengan arti adalah daya serap rendah.

Tabel 2. Daya Serap Air

\begin{tabular}{|l|l|l|l|}
\hline NO & $\begin{array}{l}\text { Mk / massa } \\
\text { kering benda uji } \\
\text { (gr) }\end{array}$ & $\begin{array}{l}\text { Mb = massa } \\
\text { basah benda uji } \\
\text { (gr) }\end{array}$ & $\begin{array}{l}\text { Daya Serap } \\
\text { Air (\%) }\end{array}$ \\
\hline 1 & 3071.400 & 3350.897 & 0.083 \\
\hline 2 & 3085.700 & 3378.842 & 0.087 \\
\hline 3 & 3028.000 & 3300.520 & 0.083 \\
\hline
\end{tabular}

\subsection{Penelitian Saluran}

Pada penelitian saluran ini menggunakan data curah hujan tahunan $2009-2018$ dengan stasiun curah hujan terdekat adalah stasiun Kedung cowek, seperti diuraikan pada Gambar 4 berikut ini. 


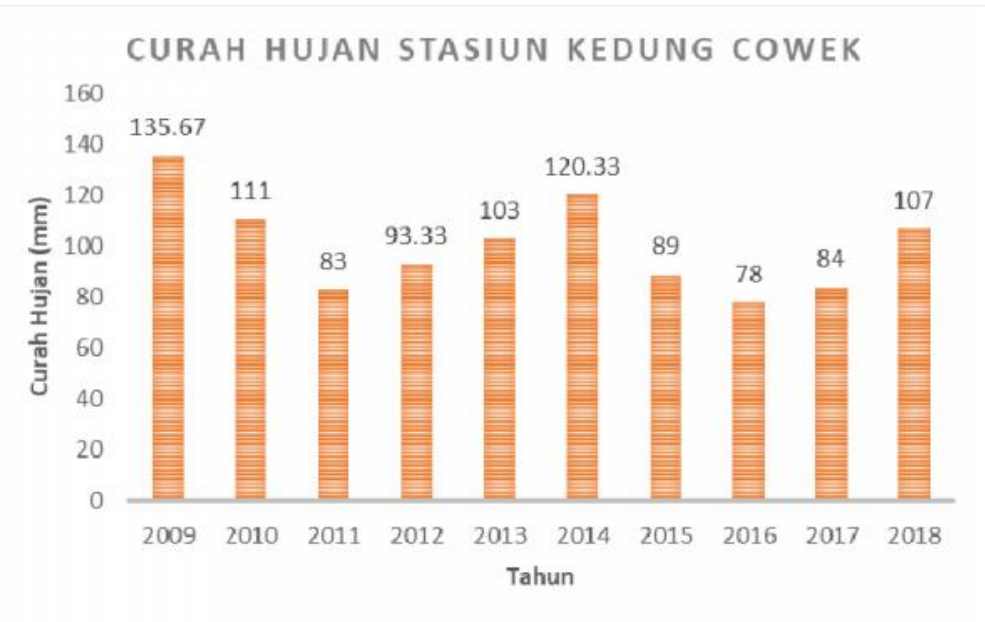

Gambar 4. Curah Hujan Stasiun Kedung Cowek

Metode perhitungan ini menggunakan log person III dimana menghasilkan curah hujan kala 2 tahun $\log \mathrm{RTr}=1.996042069 \mathrm{RTr}=99.093 \mathrm{~mm}$

Dengan Chi kuadrat menghasilkan dengan $\mathrm{Dk}=\mathbf{2}$ dan probabilitas $\mathbf{5} \%$, didapat nilai $\mathrm{X} 2 \mathrm{cr}=\mathbf{5 , 9 9 1}$. Dimana X2hit $=\mathbf{4}$, maka X2hit $<$ X2cr. Lalu dengan hasil perhitungan dari Q Rancangan atau Debit Rancangan $=0.051493258 \mathrm{~m} 3 /$ detik, lalu dengan perhitungan dari Kapasitas Saluran $=0.104237837$ m3/detik, maka Q kapasitas saluran $>$ Q Rencana bisa disimpulkan (Kondisi saluran aman atau mampu menerima $Q$ Rencana)

\section{PERHITUNGAN KEPUASAN MASYRAKAT}

Dengan total responden 75 orang, dan menyajikan 21 pertanyaan dan 5 penilaian kinerja sebagai indeks kepuasan yang akan dipilih dan dinilai oleh masyrakat sebagai tolak ukur dari kepuasan, dengan hasil kumulatif ;

Maka dari hasil tersebut dapat dibuat prosentase dari keseluruhan hasil survey kepuasan masyarakat, dimana menghasilkan prosentase.

Maka Dengan Hasil Prosentase diatas, bisa di lihat hasil dari kuisoner Indeks Kepuasan Masyarakat 54\% Sangat Puas dengan terbangunnya Infrastruktur Jalan dan Saluran.

Tabel 3. Indeks Kepuasan Masyarakat

\begin{tabular}{|c|c|c|c|c|}
\hline $\begin{array}{c}\text { Nilai } \\
\text { Persepsi }\end{array}$ & $\begin{array}{c}\text { Penilaia } \\
\text { Kinerja }\end{array}$ & $\begin{array}{c}\text { Total } \\
\text { Kumulatif }\end{array}$ & $\begin{array}{c}\text { Pembagian } \\
\text { Setiap orang }\end{array}$ & Keterangan \\
\hline 1 & Tidak Puas & 0 & 0.00 & \\
\hline 2 & Kurang Puas & 47 & 2.24 & \\
\hline 3 & Cukup Puas & 82 & 3.90 & \\
\hline 4 & Puas & 595 & 28.33 & \\
\hline 5 & Sangat Puas & 854 & 40.67 & \\
\hline \multicolumn{2}{|r}{ Total Responden } & & 75.00 & Orang \\
\hline
\end{tabular}




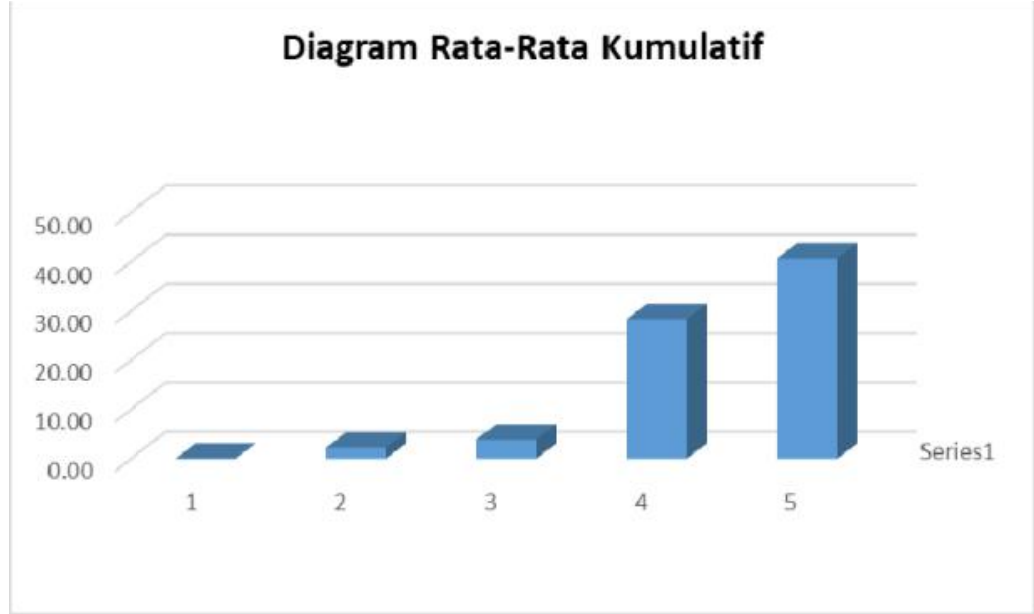

Gambar 5. Diagram Rata-Rata Kumulatif

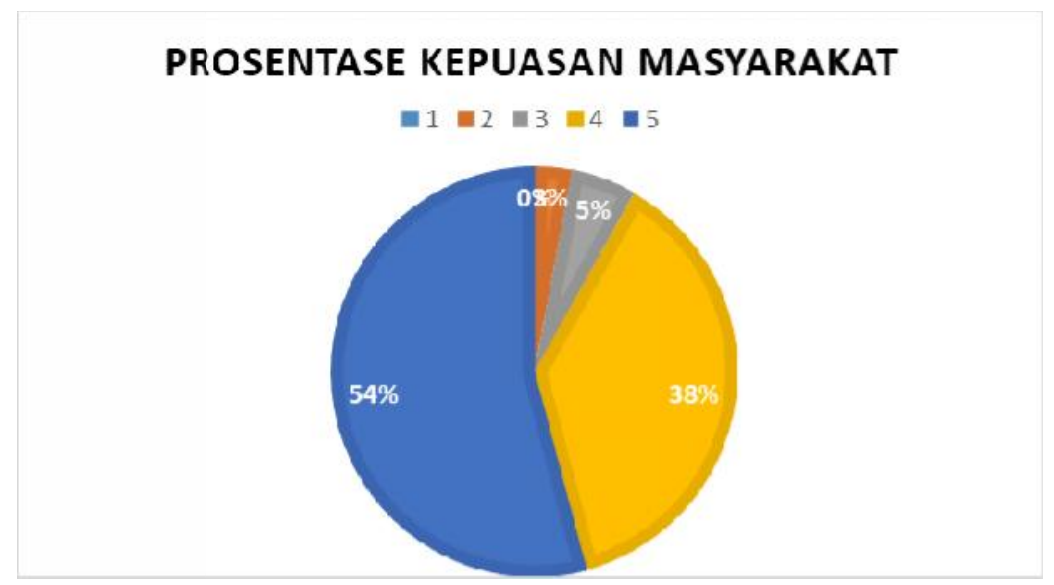

Gambar 6. Peosentase Kepuasan Masyarakat

\section{KESIMPULAN}

Dengan hasil tes tekan paving dengan tegangan hancur rata-rata $=38.22 \mathrm{Mpa}$, dan dapat di konversikan dengan table SNI Gambar 4.2.3 (Gambar Mutu Paving,dapat menunjukkan Paving Blok dengan mutu beton I, maka bisa dikategorikan layak dengan mutu beton yang tinggi.

Lalu dengan hasil uji Daya Serap air Paving Blok dengan hasil rata-rata $=0.084 \%$, bisa dikategorikan dengan daya serap rendah, dan juga bisa dikatakan layak karena daya serap yang rendah akan berpengaruh terhadap umur jalan. Maka hasil ini akan berdampak baik pada masyarakat karena umur jalan bisa tahan lama dalam 5-10 Tahun kedepan.

Untuk analisa Hidrologi dari saluran Eksisting yang ada dan dengan perhitungan Metode Log Person tipe III dengan data hujan 10 tahun,menghasilkan perbandingan Q Saluran dengan Q Rencana $0.104237837 \mathrm{~m} 3 /$ detik : $0.051493258 \mathrm{~m} 3 /$ detik, yang dimana (Kondisi saluran aman atau mampu menerima Q Rencana). Dari hasil Analisa 


\section{NAROTAMA JURNAL TEKNIK SIPIL \\ e-ISSN: 2460-3430 \\ VOLUME 3 NOMOR 2 NOVEMBER 2019}

Hidrologi ini maka Kapsitas pada saluran layak dalam kurun waktu 10 tahun kedepan dengan daya tamping volume lebih besar dari Q saluran.

Hasil Survey Kepuasan Masyarakat terhadap Infrastruktur berupa jalan dan saluran, dengan responden 75 orang, dimana dengan hasil Prosentase, Tidak puas $=0 \%$, Kurang Puas $=2.98 \%$, Cukup puas $=5.21 \%$, Puas $=37.78 \%$, dan Sangat Puas $=54.22 \%$. maka dapat disimpulkan bahwa rata-rata masyarakat setempat sangat puas dengan infrastruktur jalan dan saluran yang ada.

\section{DAFTAR PUSTAKA}

1. Badan Standarisasi Nasional. 2004. Tata Cara Perencanaan Lingkungan Perumahan Di Perkotaan (SNI 03-1733-2004). Jakarta.

2. Hariany, Zulfida \& Ir. Prof. Dr. Ir. A. Rahim Matondang, MSIE. 2014, Analisis Indeks Kepuasan Masyarakat (Ikm) Terhadap PelayananPublik Di Puskesmas Xxx, Jurnal Teknik Industri FT USU Vol 5, No. 2, Maret 2014, Departemen Teknik Industri, Fakultas Teknik, Universitas Sumatera Utara.

3. Julianto, Hendra\& Noptri Jumario, Pengaruh Pembangunan Infrastruktur Jalan Terhadap Penataan Kawasan Kumuh Pesisir Kota Tarakan, Jurnal, Jurusan Teknik Sipil,Universitas Kaltara,Tanjung Selor.

4. Sedyowati, Laksni \& Ery Suhartanto, 2015, Kajian Pengaruh Sistem Drainase Dan Ruang Terbuka Hijau Eksisting Pada Kawasan Ruas Jalan Utama Kota Malang (Suatu Upaya Pengendalian Genangan Di Daerah Perkotaan). Jurnal, Program Doktor Teknik Sipil, Minat Sumberdaya Air, Universitas Brawijaya,Jurusan Teknik Pengairan, Fakultas Teknik, Universitas Brawijaya.

5. Sembiring, Anita Christine . 2017, Uji Kuat Tekan Dan Serapan Air Pada Paving BlockDengan Bahan Pasir Kasar, Batu Kacang, Dan Pasir Halus,Jurnal,Jurusan Teknik Sipil,Universitas Kaltara,Tanjung Selor.

6. Setiawan, M. Ikhsan, 2006, Alternative Penggunaan Perkerasan Jalan Pemukiman Di Kota Surabaya Menggunakan Paving Block \& PerkerasanLentur Berbasis Efisiensi Teknis \& Biaya Pemeliharaan. Jurnal, Program Studi Teknik Sipil, Universitas Narotama Surabaya.

7. Sinulingga (1999). Pengertian sistem drainase perkotaan.

8. Stone, 1974. Pengertian Infrastruktur menurut American Public Works Association, Jurnal Infrastruktur Kodoatie.

9. Ruhaida.dan Sunarti.2012. Pemberdayaan Masyarakat Dalam Peningkatan Kualitas Permukiman Kumuh Pada Kegiatan PNPM di Kelurahan Muareja Kota Tegal. Jurnal Tenik PWK, 1: 46-65. 